\title{
Modern pedagogical aspects of training for work in the agricultural sector of Russia
}

\author{
Elena Bolotova ${ }^{1, *}$ \\ ${ }^{1}$ Don State Technical University, 1, Gagarin square, 344000, Rostov-on-Don, Russia
}

\begin{abstract}
The article highlights and analyzes the issues of the work of agricultural enterprises and personnel serving the country's agriculture in modern conditions. The work traces the development factors and tasks necessary for the successful functioning of the agro-industrial complex, training (innovative and interactive technologies training) and retraining (exchange of professional experience, social adaptation, training sessions) of highly qualified personnel, as well as government leaders, managers and young successful employees in all agricultural fields. The prospects for achieving the goals of numerous agricultural enterprises in Russia depend on how the staff works. The purpose of this work is to identify dynamic trends in the development of psychological and pedagogical aspects of training for work in the agro-industrial complex of Russia and the implementation of the tasks to achieve high professionalism, social and professional adaptation of agricultural organizations personnel. Due to the eventful saturation of the socio-political and industrial sectors of society, a change in the perception of the pace of people's lives, intensive information flows in various fields of scientific knowledge and in production over the past twenty years, the approach to training specialists with higher education has qualitatively changed. This question needs analysis and systematization of facts.
\end{abstract}

\section{Introduction}

Today, the agro-industrial complex (AIC) is presented as an important element of the national economy of Russia. It combines and includes many sectoral areas of agriculture. These usually include: production, collection and processing enterprises of agricultural products and their further promotion to the consumer market.

Russia covers an area of 17125191 square kilometers, the country's population on the territory declared by the Federal State Statistics Service on January 1, 2020 is 146745098 people, and the population density is 8.57 people per 1 sq. $\mathrm{km}$. Our country is the first in the territory. Over 400 million hectares of land are agricultural, which is more than $23 \%$.

The President Putin V.V. clearly indicated that the most important priority for Russians and the country is the State position, which is how developed our agriculture is, our independence, food security, etc. [1].

\footnotetext{
*Corresponding author: bolotovaelena2008@rambler.ru
} 


\section{The main content of the work}

The agricultural sector of Russia in the 21 st century has stepped into a new stage of development: the revival and preservation of Russian villages (staffing, infrastructure improvement, raising of wages, mobility, information, governmental support); improvement of qualification and competency-based training of personnel of agricultural enterprises' specialists (monitoring control, individual consultations, social and professional adaptation, psychological training of personnel); effective development of agriculture (smart state policy, technical modernization, investment attractiveness of the industry) and decision-making on ensuring the security and welfare of historically agrarian Russia.

The role of agro-industrial complex for the country's economy is significant, effective and strategically important. Everything that is produced and supplied for the national consumption needs in the Russian economy is estimated as $85 \%$ of all consumed products.

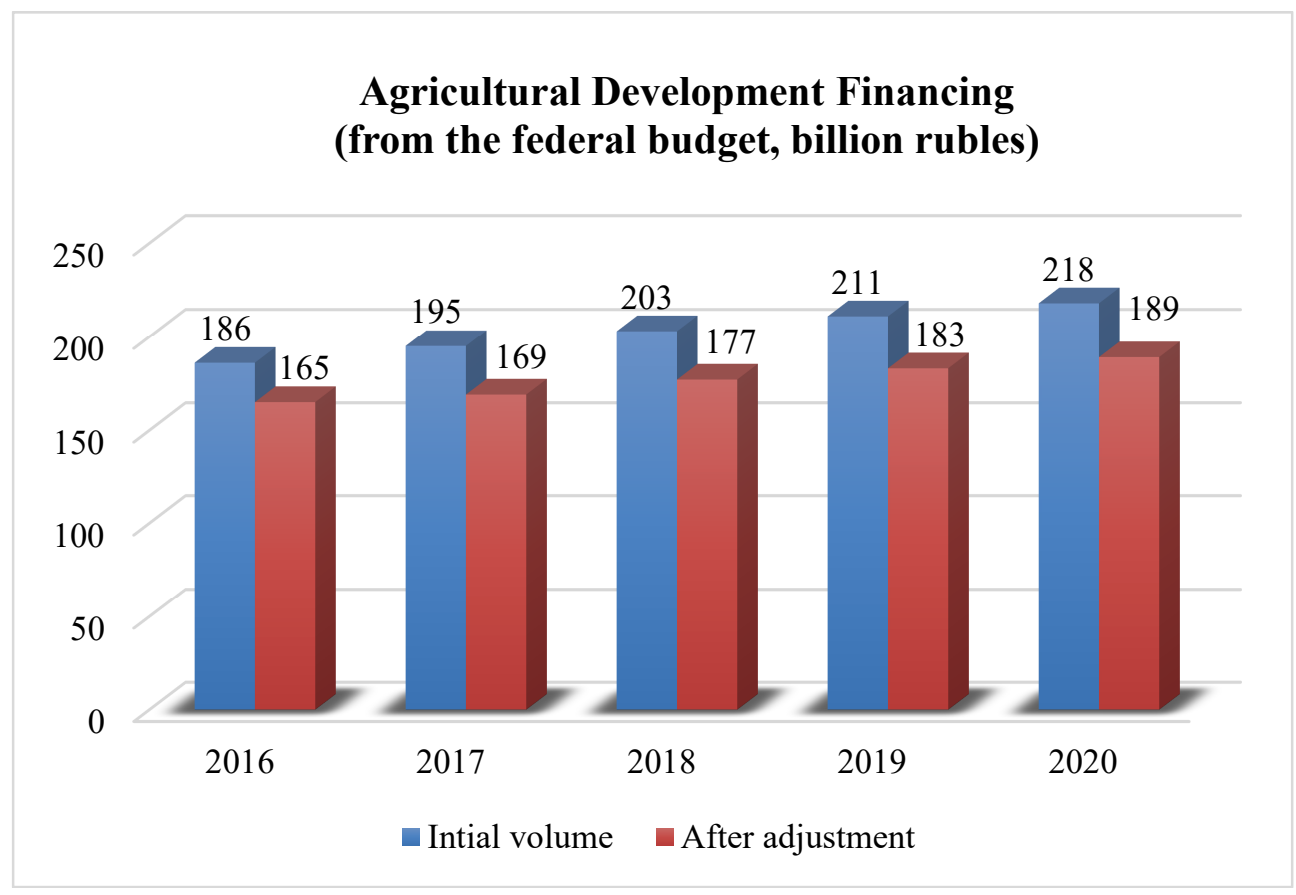

Fig. 1. Agricultural Development Financing.

The structure of the agro-industrial complex is mainly based on one sphere serving the agro-industrial complex and three production sectors.

Production areas are those that produce diverse and high-tech means of production necessary for the use and development of agriculture and for the processing of agricultural raw materials.

The first area of production usually includes:

- agricultural tractor engineering and mechanical engineering;

- manufactures producing highly efficient equipment for the food and light industry, livestock and feed production;

- production of compound feeds, high-quality mineral fertilizers;

- production for the needs of agricultural construction;

- to produce effective and high-tech equipment used in land reclamation;

- production of equipment and machinery for the feed and microbiological industries; 
- for the release of equipment for all industries that are engaged in the maintenance of the agricultural sector.

The second production sector of the country primarily includes agriculture engaged in the cultivation of various crops, animals and birds (crop production: grain farming, industrial plants, crops and plants necessary for fodder production of domestic and agricultural livestock, viticulture, horticulture, vegetable growing, potato growing; livestock: beekeeping, poultry farming, pig breeding, cattle breeding, sheep breeding, goat breeding, horse breeding, deer breeding, camel breeding, fur farming).

Secondarily, the production sector includes fisheries and forestry. All these areas are engaged in the cultivation, collection and processing of various animals and products.

The third production sector includes industries involved in agricultural raw materials processing (for light industry: flax, cotton, wool, leather, etc.; for food industry: vegetables, fruits, meat and fish of all kinds, etc.).

The infrastructure serving AIC is the fourth sector of production. This sector provides activities for the procurement, storage, transportation, sale of various agricultural products. This sector also includes the training of professional personnel for work in the country's agricultural sector and the scientific and technical services of any production.

\section{Description of the methods and experience of training the agricultural sector}

The training of qualified personnel is undoubtedly a priority for the economy of any developed or developing country. Personnel training determines the further successful activity of agricultural enterprises, the stable functioning of technical processes and much more.

Vocational training plays one of the main roles in the development of modern production technologies, which have an increased complexity of processes at all levels of agricultural production. Consequently, the personnel for all agricultural production must be highly qualified, starting with an ordinary employee to a senior specialist. Note that in the process of development of many enterprises new specializations arise, which means there is a necessity for new professions. The process of switching from one specialization to a completely new one begins and one has to take retraining (advanced training, individual psychological consultations, stress tolerance, psychological trainings for staff, and, if necessary, social and professional adaptation) of employees, and in some cases to get a new professional education. Specialists, as well as the company itself, must be constantly competitive, solvent, adapted to any technical and economic changes, to be able to withstand global and fierce competition in the professional examination of knowledge and abilities [2].

In Russia, professional training and retraining of specialists exists and operates for a long time, but it cannot be called highly effective. In the manufacturing sector of AIC, people of the «old school» with obsolete knowledge are still working. Young employees are reluctant to join the ranks of agricultural specialists. That was almost always the case, apart from individual historical periods of enthusiasm, when there were projects for the construction of great enterprises, cities, the development of new virgin lands, etc. During these periods, a surge in professional growth occurred in the country: new scientific discoveries and important achievements were made; there has been progress in the construction of new technology and in the improvement of obsolete; the list of scientific instruments and regulatory and technical documentation was updated. And at the same time, it was necessary to adapt the staff to work with sophisticated equipment.

The result of this progressive process was an increase in the number of Universities graduating specialists for work in agricultural enterprises and personnel serving the 
country's agriculture in the current conditions of the existing agro-industrial complex. Specialists after graduating from vocational schools and technical schools with the volume of their professional knowledge could not, as it was before, satisfy and meet the needs of numerous modern enterprises with highly skilled labor, since knowledge is obsolete and out of date, their value is reduced.

The agricultural education of specialists should be of high quality and meet the demanding requirements of modern manufacturers of all types of products (grown, harvested, stored, processed, sold). Modern Russian universities have a highly professional, experienced, qualified and multidisciplinary specialists who efficiently use their scientific and technical knowledge, acquired in the process of working with many of the «advanced» agro-industrial enterprises and promising agricultural holdings.

Currently, AIC specialists are trained in 58 universities of the Ministry of Education of Science of the Russian Federation, in 25 institutions of vocational education (additional professional education), 146 institutions of secondary vocational education and in 30 educational and experimental farms. 29 universities subordinate to the Ministry of Agriculture of Russia, have agricultural faculties that train professional personnel for the agricultural profile. But so far, the agricultural sector lacks about 80 thousand workers with higher specialized education.

This is of course statistics, but in reality the figure is larger, as the youth in the village does not want to work. Only 3 to 20 percent of graduates remain working in the countryside even if their studies have been paid from the federal budget.

Agricultural students at universities of the Ministry of Agriculture of Russia are taught in 6 core areas of basic knowledge, in 25 grouped specialties, areas of training and retraining. In the Bachelor's program, 63 areas are engaged in training, and in the Master's program, 42 areas and 10 major specialties.

The basic directions and settings for training agricultural specialists include: agronomy, agrochemistry, soil science, agricultural engineering, production technology and processing of agricultural products, livestock production, veterinary production, gardening, etc.

It is necessary to understand that education is not only studying at a higher educational institution. In agriculture, both family and professional continuity are important. But, despite the existing difficulties, the country's agriculture is developing successfully.

Significant changes have started since the beginning of large-scale modernization in the educational area: educational institutions study and master new educational and training technologies, a market economy, innovative and foreign economic activity, provide legal support for AIC, business issues, management, lending and credit, taxation and much more.

Ministry of Agriculture of the Russian Federation is constantly continuing work on optimizing the system of higher agricultural education: there is an accession (reorganization of universities by unification) of technical schools (22 units), advanced training institutions (41 units) and one research institute. Thus, the status of an agricultural university is increasing.

The strategy of innovative and effective development of rural areas of Russia for the future period (up to 2030) will require the involvement of specialists of a qualitatively new and higher level, professionally trained, creative and active, sociable, able to solve quickly and effectively not only standard tasks, but also non-standard management situations. Therefore, along with the highly specialized staff in the manufacturing sector, engineers who have versatile organizational skills, are able to work both in production complexes and in small work teams with the implementation of strategic tasks in the practical sphere of activity are required. It should be noted that the vector of the potential for the innovative development of higher education and the traditional training of specialists for the agroindustrial complex in the future is aimed at humanitarian, social, historical and everydaypragmatic, sociogenetic (social development factors, socialization processes) and relevant 
network, technological and phenomenological (consideration of specific experience ) technologies, as they allow a young specialist to realize professional competencies as efficiently as possible, demanded by modern society.

Potential specialists are required to possess the ability to identify, develop, understand, resolve and verify problems in structural, psychosocial, comprehensively oriented social work and medical and social assistance. Also, specialists must confidently possess the modern skills of the infrastructure special analysis that guarantees social well-being and well-being of numerous socio-cultural groups representatives; the ability to determine the scientific and practical value of effectively solved and actively discussed research problems in order to organize and coordinate them, ensuring the social well-being of society.

The training of new staff members involves a well-organized and streamlined learning process when transmitting to students the current base of legal and methodological information, practical skills for the future implementation of knowledge in the selected area of agricultural production.

Socio-psychological trainings are usually considered a high-quality toolkit in achieving the defined goals. Short-term trainings, as a psychological and pedagogical aspect of personnel training for the agricultural sector, are a positive burden.

Trainings are methodically arranged in a multi-stage [6] a system that includes the following stages:

1st stage - demand, relevance, effectiveness of the educational process are identified and established (I am an intern, how will I gain skills, knowledge, etc.);

2nd stage - the theoretical foundation should be «grounded» to the foundation of the practical activities of each participant of the trainings;

3rd stage - it is necessary to make a plan for introduction of each trainee to the future position, understanding the goal and objectives to achieve certain results;

4th stage - mentors (training leaders) share their practical work experience, comparing it with the training preparatory program with their direct participation;

5 th stage - solution of the issue of the further work of the trainee in a new position, the quality of his success, focus and prospects of activity, which is the most difficult psychological and pedagogical aspect of training highly qualified personnel in the modern development of the agro-industrial complex.

All these psychological and pedagogical aspects should optimize personal and professional qualities of the trained participants by activating their autopsychological resources (autopsychological competence) of the individual, complementing each other with a meaningful and technological meaning.

In studies of the nature of the development of socio-psychological trainings, we noted that this topic is actively discussed by many foreign authors. Since 1994, the American Society for Training \& Development has been uniting nearly 70,000 collective and individual members from 100 developed countries of the world, developing and organizing trainings in various areas.

The development of group interactions and the compilation of the methodology of socio-psychological trainings are carried out by many specialists for training personnel in various areas of life skills using psychoanalytic ideas (Manfred Forverg, Karl Rogers, Warren Bennis, Herbert Shepard and others).

The practice of the Training groups is based on the discussion (the subject is really existing interpersonal relationships) among the participants, as well as the study of the discussion dynamics by the group (the task is to analyze the discussion processes). According to the position of I.V. Vachkova and S.D. Deriabo, socio-psychological trainings can be attributed to the method of obtaining knowledge «here and now» Yu.N. Emelyanov insists that the term «training» should be positioned with the designation of various 
methods of development and mastering the abilities of any type of activity (communication, compatibility, negotiations, sales, team, conflict-free behavior, etc.).

Most of the socio-psychological training methods can be described as the therapeutic effect of group counseling and interaction (the expansion of interpersonal contacts, complicated forms of communication, problems of the modern development of society, etc.).

Modern technology of socio-psychological training occupies a pronounced place among the new interactive methods that are actively used in the generally accepted educational process. The educational way of the process of training specialists for the agro-industrial complex requires to include a set of disciplines that clearly contain a specific focus on the development of certain managerial competencies. Thus, engineering education, using the humanitarian potential of knowledge, provides training for highly qualified personnel for the agricultural sector, driven by professional standards developed by numerous employers, taking into account current requirements in the context of constantly changing socioeconomic conditions.

Experience shows that the necessity for training and retraining of professional personnel in an organization may arise in the following cases:

- in order to acquire a second profession;

- after the necessary transfer of a specialist to another workplace;

- in order to periodically improve the qualifications of employees and familiarize themselves with new scientific and technical documentation and experience;

- after a person enters a new job for his adaptation in the workplace and in the team;

- in order to eliminate violations and shortcomings in the training of long-standing specialists identified during inspections in order to increase the level of staff compliance with basic requirements at workplaces;

- in order to expand the professional capabilities of the specialist and establish the framework of the possible scope of some type of his professional activity;

- in order to promote a certain employee in the career and to replenish the reserve of highly educated personnel.

Traditionally, training can be carried out in three well-known ways:

- in-service and internship (without interruption and during the work of the enterprise or company, inside any production);

- a variety of specially organized training courses on a short-term release basis break and an internship (outside the work of the company), organized by qualified teachers with wide experience, based on the needs of the enterprise;

- by self-training in order to update practical and theoretical knowledge with independent acquisition of new knowledge or training in higher or other educational institutions;

- organisation of business trainings providing an opportunity to determine the necessary complex of the proposed modern services, which are adjusted to the needs of a particular organization.

Domestic and foreign experience has identified three basic concepts in the training of professional specialists: the concept of personal training; the concept of specialized, competent training and the concept of multidisciplinary and ramified training.

In the agriculture reform period, the human factor underwent a severe deformation: the demographic situation worsened; objects of socio-cultural infrastructure were reduced and social services of the population worsened; agricultural labor depreciated; job cuts increased; the level of employment in rural areas has decreased; the agricultural labor market has narrowed; there was an increase in the tension coefficient.

Therefore, the State's leadership took the necessary measures to train and retrain agricultural workers who are susceptible to the development of modern technologies, 
oriented towards their effective creation, capable of participating in innovative processes, and also able to comprehensively implement important principles of state support and regulation, which are expressed in the following:

- the introduction of direct public investment in the development of all types of education, various fields of science;

- iproving the training and retraining of qualified specialists for the implementation of the innovative technological model of development and normalization of the situation in agriculture;

- development of rural territories on the basis of modern scientific developments and implementation, stable comprehensive restoration programs of joint state, municipal and private partnerships;

- maintaining and increasing employment of the rural population through the active development of small agribusiness enterprises, while creating its modern infrastructure.

The Introduction of modern scientific and information technologies as a regular practice, will allow young specialists to achieve a high level of competency in techniques and methods of work, effectiveness in marketing and management knowledge, the ability to correctly substantiate and make promising decisions in order to provide quality training and retraining of agricultural specialists of any professional level.

The main parts of the training and retraining structure (psychological and pedagogical aspect) are such basic modules as: informational (providing basic knowledge on pedagogy, presentation of informational and advertising messages); analytical (self-reflection in theoretical and practical training, analysis of data on supplies, stocks, customer relations); operational (cognitive, shaping skills, optimizing the process of reduction in operational risks) and motivational (the formation of an individual professionogram, awareness of the value, importance of knowledge and cognition, career self-regulation mechanisms, etc.). These days, the modular approach to building the curricula of educational institutions is based on the principles of individuality, consistency, the acquisition of specific competencies, logical completeness, etc.

\section{Conclusion}

In conclusion, we can say that agriculture was, is and will be the leading industry in the material production of our country because it is the guarantor of national food security. Today in Russia there is a chance for successful evolution of social and economic potential of agriculture in the agro-industrial sector.

At the present stage of transformations in all areas of education (special, higher, etc.), the process of a clear rapprochement of humanities and technical knowledge has intensified. This process is expressed in new approaches to the training and retraining of new time specialists who has knowledge of advanced educational and professional technologies, and are able to quickly navigate in the core space in the main scientific areas of the agro-industrial complex.

\section{References}

1. V.V. Putin, Support for agriculture is our conscious policy 3, 2-3 (2010)

2. B.Ch. Meskhi, M.A. Izotov, Y.S. Knyazeva, T.V. Simonyan, European Research Studies Journal 19(2), 64-70 (2016)

3. E.N. Makhmutova, M.M. Andreeva, T.A. Dmitrenko, Integration of Education 22(1), 91-106 (2018) http://edumag.mrsu.ru/index.php/en/articles-en/77-18-1/621-10-155071991-9468-090-022-201801-06 
4. Yu.N. Emelyanov, Theory of formation and practice of improving communicative competence: dis. (L., 1990)

5. I.M. Gorodetskaya, 15th International Conference on Interactive Collaborative Learning (ICL) (Villach, Austria, 2012) https://ieeexplore.ieee.org/document/6402121

6. N.M. Glukhenkaya, Research of the Corporate HR Management System, Monograph (Vědecko vydavatelské centrum «Sociosféra-CZ», Prague, 2014)

7. L.V. Orinina, I.V. Kashuba, I.V. Samarokova, Perspektivy Nauki i Obrazovania 37, 316-326 (2019) https://pnojournal.files.wordpress.com/2019/02/pdf_190123.pdf

8. Organic Agriculture, US Department of agriculture. website (2015) http://www.usda.gov/wps/portal/usda/usdahome?navid=organic-agriculture

9. D. Holwerda, P.T. Voskuy, Ministry of economy, agriculture and innovation, www.rijksoverheid.nl/ministeries/eleni

10. N.L. Krivtsova, Modern problems of science \& education 6, 501 (2012)

11. M. Sheehan, N. Thomas Garavan, R. Carbery, European Journal of Training and Developvent (2014)

12. L.K. Ilyashenko, Z.V. Smirnova, M.P. Vaganova, N.S. Prokhorova, N.S. Abramova, International journal of mechanical engineering and technology, 1097-1105 (2018)

13. G. Newstrom, That davecat. Organizational behavior. Human behavior in the workplace (Split., Peter, 2000) http://netref.ru/9-chaste-i-osnovi-organizacionnogopovedeniya.html?page $=27$

14. Agriculture and Agri-Food Canada, http://www.agr.gc.ca/eng/home/?id= 1395690825741

15. M. Falaki, H. Fami Shabanali, H. Iravani, H. Mohammadi Movahed, Sci. Technol. Agric. Nat. Res. 12(43), 253-65 (2008)

16. The world of organic agriculture. Statistics \& emerging trends 2016, FIBL \& IFOAM - organic international (2016) https://shop.fibl.org/fileadmin/documents/shop/1698organic-world-2016.pdfP, //moluch.ru/th/7/archive/26/1147/

17. Synthesis of ex ante evaluations of rural development programmes 2014-2020. Final Report. European Union (2015) 